\title{
Assessment of tsunami hazards for the Central American Pacific coast from southern Mexico to northern Peru
}

\author{
B. Brizuela ${ }^{1, *}$, A. Armigliato ${ }^{2}$, and S. Tinti ${ }^{2}$ \\ ${ }^{1}$ Istituto Nazionale di Geofisica e Vulcanologia, Rome, Italy \\ ${ }^{2}$ Dipartimento di Fisica e Astronomia, Università di Bologna, Bologna, Italy \\ * formerly at: Dipartimento di Fisica e Astronomia, Università di Bologna, Bologna, Italy \\ Correspondence to: B. Brizuela (beatriz.brizuela@ingv.it)
}

Received: 11 June 2013 - Published in Nat. Hazards Earth Syst. Sci. Discuss.: 28 June 2013

Revised: 13 June 2014 - Accepted: 13 June 2014 - Published: 29 July 2014

\begin{abstract}
Central America (CA), from Guatemala to Panama, has been struck by at least 52 tsunamis between 1539 and 2013, and in the extended region from Mexico to northern Peru (denoted as ECA, Extended Central America in this paper) the number of recorded tsunamis in the same time span is more than 100 , most of which were triggered by earthquakes located in the Middle American Trench that runs parallel to the Pacific coast. The most severe event in the catalogue is the tsunami that occurred on 2 September 1992 off Nicaragua, with run-up measured in the range of $5-10 \mathrm{~m}$ in several places along the Nicaraguan coast. The aim of this paper is to assess the tsunami hazard on the Pacific coast of this extended region, and to this purpose a hybrid probabilistic-deterministic analysis is performed, that is adequate for tsunamis generated by earthquakes. More specifically, the probabilistic approach is used to compute the Gutenberg-Richter coefficients of the main seismic tsunamigenic zones of the area and to estimate the annual rate of occurrence of tsunamigenic earthquakes and their corresponding return period. The output of the probabilistic part of the method is taken as input by the deterministic part, which is applied to calculate the tsunami run-up distribution along the coast.
\end{abstract}

\section{Introduction}

This paper is concerned with the tsunami hazard in the Extended Central America (ECA) region that extends from southern Mexico to northern Peru. Earthquakes, landslides, mudslides and hurricanes are among the most relevant nat- ural hazards in the ECA and are well known to the population. Instead, tsunamis are underrated, in spite of the occurrence of recent large events. The last tsunami occurrences are the weak, non-damaging events of 26 August 2012 and 7 November 2012 that were observed in southern El Salvador, while the last destructive event is the 2 September 1992 tsunami ravaging the Nicaraguan coast and causing about 170 fatalities and leaving 13000 homeless, with run-up values ranging between 2 and $10 \mathrm{~m}$ (see field surveys by Abe et al., 1993; Baptista et al., 1993; Satake et al., 1993). In addition to studies on this specific case (e.g. Satake, 1994; Piatanesi et al., 1996), this event triggered tsunami research in the ECA, including the compilation of a regional tsunami catalogue (Molina, 1997) for Central America (CA), that is the region going from Guatemala to Panama, and empirical, statistical and deterministic tsunami assessments. It was established that the ECA region was affected mostly by moderate events, but also by some destructive tsunamis (see e.g. Fernández et al., 2000, 2004; Álvarez-Gómez et al., 2012) and that all countries in the ECA are likely to be hit by tsunami waves in the future. Preliminary tsunami hazard estimations were performed on the Pacific coast in 2000 by the Centro de Investigaciones Geofísicas (CIGEFI) de la Universidad de Costa Rica, the Red Sismológica Nacional (RSN: ICE-UCR), the Instituto de Sismología, Vulcanología, Hidrogeología y Meteorología de Guatemala and the Institute of Solid Earth of the University of Bergen, Norway. It has been found that Nicaragua, El Salvador, and Honduras are the most prone coasts to be hit by tsunamis. Numerical simulations were also carried out in 2004 by the Central American Seismological Centre (CASC), the Centro de 
Investigación Cientifica y Educación Superior de Ensenada (CICESE) and the Escuela Centroamericana de Geología de la Universidad de Costa Rica in order to study historical tsunamis.

In this paper, an assessment of the tsunami hazard along the Pacific coast from Mexico to northern Peru is performed through a hybrid probabilistic-deterministic analysis, following a method that was first introduced for the Italian coasts by Tinti (see Tinti, 1991a, b; see also El Alami and Tinti, 1991) and that is conceived for tsunamis generated by local earthquake sources. The statistical approach aims to estimate the Gutenberg-Richter (GR) coefficients of the main seismic tsunamigenic zones of the area in order to evaluate the annual rate of occurrence of tsunamigenic earthquakes and their corresponding return period. The deterministic analysis is then used to compute the tsunami run-up distribution along the coast, corresponding to a given annual rate of occurrence of a tsunamigenic earthquake. In a very general sense, this is the type of result that is expected from what is usually referred to as probabilistic tsunami hazard analysis (PTHA). In the last decade or so, PTHA approaches have been discussed, among others, by Geist and Parsons (2006), Power et al. (2007), González et al. (2009), and ÁlvarezGómez et al. (2013). In the more general understanding, PTHA combines statistical techniques, usually derived from the seismological research field, with advanced tsunami inundation modelling. This second part needs very detailed computational grids created starting from high quality and very high-resolution topography-bathymetry data sets. For those coastal areas where these databases are available, and hence suitable and reliable computational grids can be created, using properly benchmarked inundation models and running hundreds to thousands of tsunami simulations can produce very detailed results in terms of hazard assessment expressed as a level of inundation corresponding to given return times in different locations. Our approach is much less demanding in terms of resources and time, and can be seen as a first simplified but sound step to estimate the tsunami hazard.

To establish the framework of this analysis, the paper contains a brief summary of the geotectonics of the ECA region, a detailed description of the CA tsunami catalogue (Molina, 1997), and also a mention of the tsunami events in the ECA. In the second stage, the paper focuses on the seismic catalogues available for the ECA, and on the data chosen to perform the statistical analysis.

\section{Geotectonic setting}

The ECA is located at the isthmian portion of the American continent. Its main land lays on the North American plate and on the Caribbean plate, whereas its Pacific coast runs parallel to the Middle American Trench, where the Cocos plate subducts beneath the Caribbean plate and the Nazca plate subducts beneath the South American plate.

Geologically speaking, the ECA can be divided into the northern and southern ECA. Guatemala, Honduras, El Salvador and northern Nicaragua can be included in the northern portion, whereas southern Nicaragua, Costa Rica and Panama are considered the southern portion. The northern ECA has a continental-style crust and it contains Palaeozoic or older rocks and sediments from the upper Palaeozoic, the Mesozoic and the Tertiary. In contrast, a Cretaceous-type crust composes the southern portion, with thick marine and tertiary volcanic sediments on the top. This portion is a transition zone from pure oceanic to continental crust (Bommer and Rodriguez, 2002).

The Pacific coast of the ECA runs parallel to the Middle America Trench, where the Cocos plate subducts beneath the Caribbean plate. Although the Cocos plate has approximately the same age along the trench, its morphology changes dramatically from place to place. The region is characterised by a smooth slope at the Nicaraguan coast, a very steep slope in Guatemala and a transition zone along the Salvadoran coast. The smooth slope is built of en echelon terraces, whereas the steep slope contains several canyons and gullies. The transition zone can be described as a rough terrain variable in width (Ranero et al., 2004).

The subduction zone of the ECA can be classified as an intermediate stage between the Mariana and the Chilean style subduction zones. It has a steep dip that shallows from southern Nicaragua to northern Guatemala and the overriding zone (the Caribbean plate) is slightly extensional (Dewey et al., 2004).

Recent research has established the plate kinematics of the ECA through the use of GPS observations. The North American plate moves to the southwest at rates of about $21 \mathrm{~mm}$ year $^{-1}$, whereas the Caribbean plate moves at about $9 \mathrm{mmyear}^{-1}$ to the southeast and the Cocos plate moves northeastward at approximately $70 \mathrm{~mm}_{\text {year }}{ }^{-1}$ (Phipps Morgan et al., 2008). The Cocos-Caribbean and North American junctions are not an ideal stable triple junction, since the Cocos plate seems to be mechanically stronger than the North American and Caribbean plates. As a consequence, the roll-back of Cocos plate's slab is continuous along the Middle American Trench, which also means that the forearc motion must also be continuous along the junction (Phipps Morgan et al., 2008).

At the Caribbean coast, the northern ECA's geomorphology is characterised by sierras formed of several sub-parallel ranges, composed of metamorphosed deposits, separated by faults and grabens. At the Pacific coast, volcanic ranges and plateaus are located in Nicaragua, El Salvador and parts of Honduras and southwest Guatemala (Bommer and Rodriguez, 2002).

There are basically three seismogenic areas in the northern ECA. First, the Cocos-Caribbean subduction zone that produces the largest earthquakes in the region, and 
the Cocos-North American convergence zone. Second, the North America-Caribbean interaction zone, and third the upper crust seismicity also associated with the quaternary volcanoes. The southern ECA seismicity is due to the interaction of three main tectonic plates, namely Nazca, Caribbean and South American plates, and several microplates, like the Panama and North Andes plates at their boundaries (Bommer and Rodriguez, 2002). As expected in subduction zones, the main focal mechanism of the earthquakes in the trench is thrust and inverse (Álvarez Gómez, 2009), but also strike-slip earthquake occurrences are recorded. It is remarkable how common outer-rise normal earthquakes are here, occurring in larger proportions than in several other subduction regions (Álvarez Gómez et al., 2012).

\section{Observed tsunamis}

For illustrative purposes, it is convenient to focus first on tsunami observations in CA from Guatemala to Panama and then on events in the ECA region, including Mexico in the north and Colombia and Ecuador in the south.

The CA tsunami catalogue compiled by Molina (1997) contains 49 events that occurred between 1539 and 1996 and that were observed in a geographical window covering mainly the region from Guatemala to Panama. Information for each event includes the date, tsunami parameters and tectonic region of the source. Maps of the region struck by the tsunami are normally shown. In case of earthquake generation, seismic parameters and epicentre maps are given and in some cases macroseismic maps are also included. It is noted that one of the catalogue events is definitely not a tsunami but it is a lahar occurrence: following an earthquake on $3 \mathrm{Au}-$ gust 1951, a side wall of the volcanic lake on the top of Cosigüina volcano collapsed and muddy waters inundated the coastal town of Potosi located at the foot of the volcanic edifice.

If we exclude this event from the catalogue and consider 4 more tsunamis that occurred after 1992 (the time limit of Molina's catalogue) - namely the 2010 Chile and 2011 Japan tsunamis that reached CA, the 2012 El Salvador (26 August) and Guatemala (7 November) tsunamis mentioned in the introductory section - the total number of tsunamis of the modified Molina's catalogue considered in this paper is 52. As many as 39 events are well documented and all are due to earthquakes, whereas the others have lower reliability and are debatable. Of these, six tsunamis are associated with an unknown cause.

Most of the above tsunamis (i.e. 26 well documented and 14 debatable) were observed in the Pacific coast. Only 5 were caused by remote sources (namely the earthquakes of 1906 in Ecuador; 1957 in the Aleutian islands; 1960 and 2010 in Chile; 2011 in Japan), while the remaining are associated with local earthquakes that occurred at the Middle American Trench, in the fracture zone of the so-called Panama plate, at the boundaries of the North American and South American plates or are due to shallow faults. All of the tsunamis observed at the Caribbean coast of CA were associated with earthquakes (Fernández et al., 2000; Harbitz et al., 2012). Tsunamis associated with submarine landslides, terrestrial landslides or volcanic eruptions have not been reported in the area. Submarine eruptions are not a possible tsunamigenic source in the region, because there are no active submarine volcanoes in the area.

The Molina's tsunami catalogue is divided in three main time periods that correspond to the 16th-18th, 19th and 20th centuries. If we keep the same subdivision and extend the last period to cover the interval until 2013, we see that only 4 tsunamis fall in the first period, 11 in the second and 37 in the third, which shows that the modified Molina's catalogue is largely incomplete with a critical underreporting in the first two parts. The tsunamis compiled in the catalogue have magnitudes varying between 0 and 2.5 according to the Imamura-Iida scale (e.g. Iida et al., 1967; Iida, 1970) and the damage reported describes the destruction of small ships, coastal infrastructure and sometimes the destruction of small villages. The largest magnitude and the most severe damage is due to the relatively recent 1992 tsunami in Nicaragua.

Since Molina's catalogue refers only to CA, it has to be extended to the neighbouring regions to cover the whole ECA region.

According to Singh et al. (2008), there have been several moderate tsunamigenic earthquakes along the Pacific Coast of Mexico in the last century. They have mainly triggered local tsunamis of limited extent, but there is also evidence of the occurrence of a much larger event along the coast of Oaxaca on 28 March 1787. The description of such an event by Suárez and Albini (2009) suggests a sea withdrawal of over $4 \mathrm{~km}$, followed by a flood of about $6 \mathrm{~km}$ near the Alotengo Lagoon. The waves also transported inland some fish and shellfish at Pochutla (nowadays Puerto Angel) and also at the coastal area south of the city of Tehuantepec. Farreras and Sanchez (1991) believe that the historic accounts of the last three centuries prove that locally generated tsunamis pose a significant threat to the southwestern coast of Mexico and CA.

Moving to the southernmost portion of the ECA, one sees that the interaction zone between the North Andes and the Nazca plates is very active, especially in the coastal area belonging to Colombia and northern Ecuador. During the last century four major earthquakes occurred in this zone in 1906, 1942, 1958 and 1979, and they all triggered destructive tsunamis (Restrepo and Otero, 2007). On 12 December 1979, an $M_{\mathrm{w}}=7.9$ earthquake occurred at the EcuadorColombian boundary, generating a tsunami that caused only light damage in Ecuador but was very destructive along the Colombian coast (Espinoza, 1992). The death toll between the earthquake and the tsunami was 452 victims. The waves hit the coastal area from Tumaco to Guapi. The island of San Juan, located $60 \mathrm{~km}$ north from Tumaco, was the most 


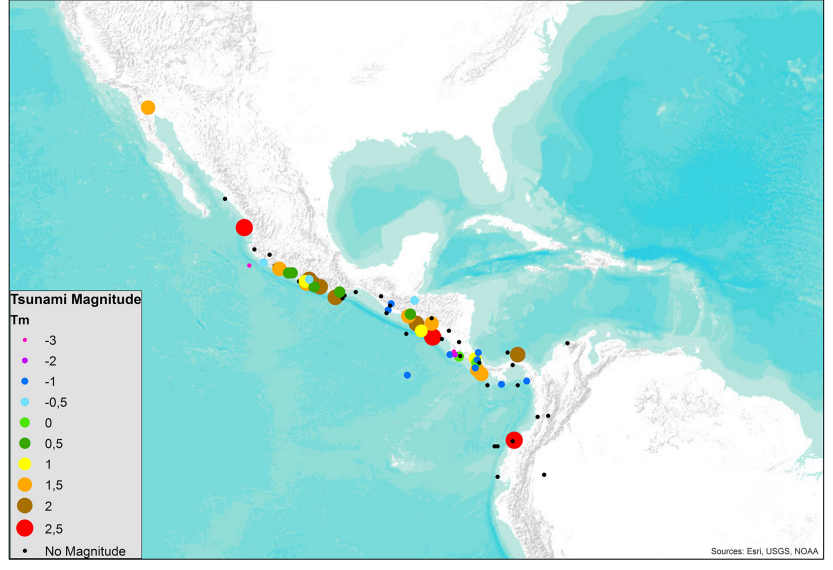

Figure 1. Tsunamis in the ECA based on the modified Molina's catalogue (Molina, 1997) and on the NOAA-NGDC Tsunami Event and Run-up Databases. Imamura-Iida tsunami magnitude is shown.

severely affected area and was completely destroyed by the tsunami. The Island of Guano was completely submerged after the flooding, whereas at northwestern Tumaco local floodings were reported (Restrepo and Otero, 2007).

The information for the events affecting the added areas of the ECA was taken from the NOAA/NGDC (National Oceanic Atmospheric Administration/National Geophysical Data Center) tsunami event (http://www.ngdc.noaa.gov/ nndc/struts/form?t=101650\&s $=70 \& d=7$ ) and tsunami runup databases (http://www.ngdc.noaa.gov/nndc/struts/form? $\mathrm{t}=101650 \& \mathrm{~s}=167 \& \mathrm{~d}=166$ ). With this addition, the total number of tsunamis in the catalogue can be incremented from 52 to 106. All the added events are due to local earthquakes in the Pacific, and occurred after 1539, so that the total time span of Molina's catalogue is not changed.

In Fig. 1 all reported tsunamis in the ECA are shown, that is the ones reported in the modified Molina's catalogue, together with the ones from the NOAA-NGDC Tsunami Event and Run-up Database.

The number of events contained in the tsunami catalogue assembled for this paper is not large enough to allow for an accurate statistical analysis and to lead to reliable tsunami hazard estimates. However, considering that tsunamis in the ECA region are mainly triggered by earthquakes, one can restrict the attention to the hazard only due to earthquakeinduced tsunamis and make use of the earthquake catalogues to compute statistics on tsunamis. This is the method adopted in this paper.

\section{Statistical analysis of a suitable earthquake catalogue}

There are several seismic catalogues that contain events registered in the ECA (see Table 1). Some cover only small areas of the ECA, while some others contain solely recent events or events with high magnitude. Epicentres of the

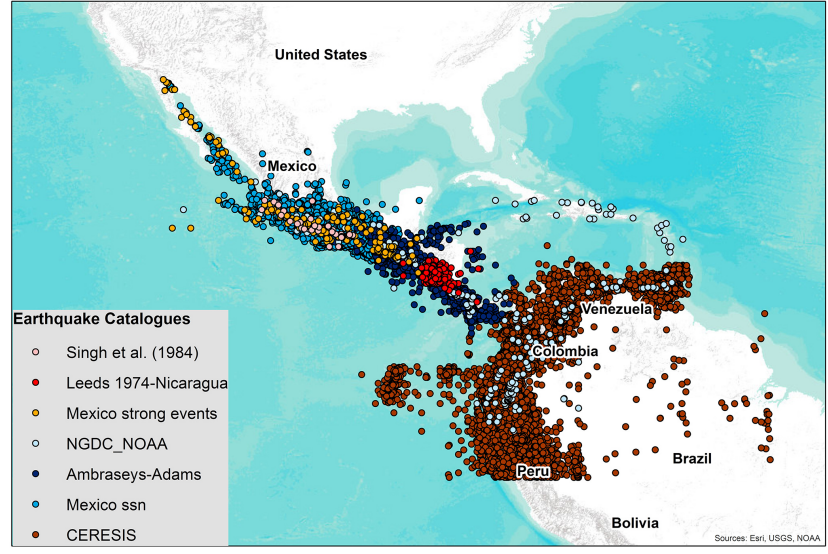

Figure 2. Epicentres from the seismic catalogues of the ECA.

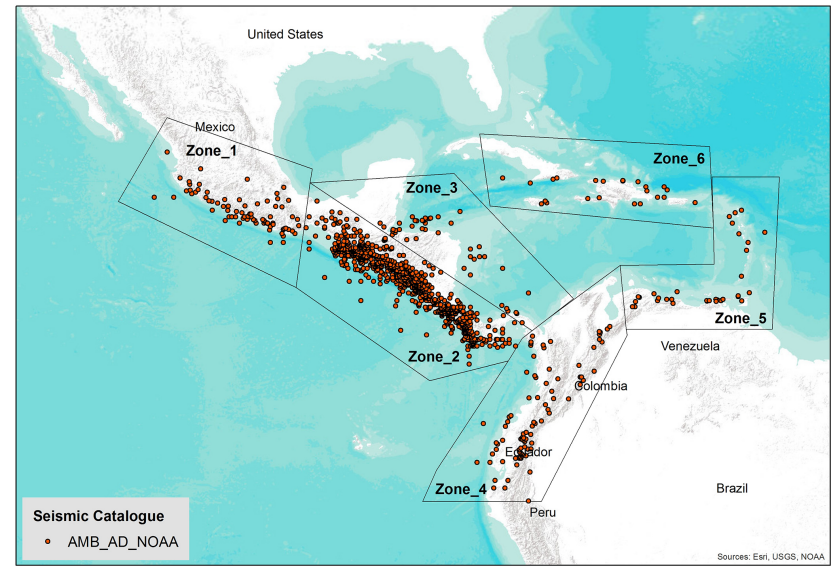

Figure 3. Epicentres of the joined AMB-AD-NOAA seismic catalogue, and seismic zones of the ECA.

earthquake catalogues that were available for our study are plotted in Fig. 2.

The catalogue compiled by Leeds (1974) contains 399 events that occurred between 1520 and 1973 with magnitude varying from 3.7 to 7.7. The catalogue covers Nicaragua only. The Ambraseys and Adams (2000) catalogue contains about 1800 events that occurred in CA from 1898 to 1995 , the magnitude values (Ms) varying from 3 to 7.9. The catalogue compiled by Singh et al. (1984) contains 31 shallow events with magnitudes between 7 and 8.4. The NOAAUSA catalogue contains about 1400 events that occurred from 1471 to 2008 . The magnitude range goes from 1.6 to 9.5 and covers the whole American continent. The catalogue compiled by the "Centro Regional de Sismología para America del Sur" (CERESIS, http://www.ceresis.org/portal/catal_ hipo.php) contains more than 1000 events that occurred in South America. The "Mexico noticeable earthquake catalogue" (Kostoglodov and Pacheco, 1999) contains 181 events whose magnitude varies between 6.4 and 8.2. Last, but not least, the Mexico SSN (SSN, Servicio Sismologico Nacional, 
Table 1. Seismic catalogues of the ECA.

\begin{tabular}{cllcc}
\hline Number & Authors & Area covered & Time covered & Earthquake type \\
\hline 1 & Leeds (1974) & Nicaragua & $1520-1973$ & all \\
2 & Ambraseys and Adams (2000) & Central America & $1898-1995$ & all \\
3 & Peraldo and Montero (1999) & Not available & $1500-1899$ & \\
4 & Rojas (1993) & Not available & $1502-1992$ & \\
5 & Singh et al. (1984) & Southern Mexico, Pacific & $1900-1981$ & shallow \\
6 & NOAA & Mexico, Central and South America & $1471-2008$ & all \\
7 & CERESIS & South America & $1530-1991$ & all \\
8 & Mexico noticeable earthquakes & Mexico & $1900-1999$ & $m>6.5$ \\
9 & Mexico SSN & Mexico & $1998-2008$ & all \\
\hline
\end{tabular}

http://www.ssn.unam.mx/) catalogue contains about 9400 instrumental events from 1998 to 2008 , with a magnitude range from 2.3 to 7.6 .

The earthquake catalogue selected to carry out the analysis presented in this paper is the Ambraseys and Adams (2000) catalogue (hereafter called the AMB-AD catalogue), given that it is a specific study of the seismicity of CA and has a large number of events with specified magnitude values.

In order to increase the number of events contained in the AMB-AD catalogue, and also to cover a larger temporal and spatial window, the NOAA catalogue events were added, with the provision that if one event was found to be contained in both catalogues, generally the NOAA event was deleted. Events with depth greater than $100 \mathrm{~km}$ were removed, given that they are unlikely to cause tsunamis. Following this procedure, a seismic catalogue (from now on AMB-AD-NOAA catalogue) was produced (see Fig. 3) containing 1931 events that took place from 1530 to 2012 .

The AMB-AD-NOAA catalogue was divided into six zones, considering the geographical location and the probable tectonic unit related to the earthquakes. The first zone covers the Pacific coast of southern Mexico, the second zone extends along the Pacific coast from southern Mexico to Panama, the third zone covers the Atlantic coast from southern Mexico to Panama, the fourth zone goes from southern Panama to the Pacific coast of Ecuador and northern Peru, the fifth zone covers the Atlantic coast of Venezuela and the lesser Antilles and the sixth zone covers Cuba and the Antilles (see Fig. 4). Events within zones 1, 2 and 4 are related to the subduction zone of the Middle American Trench, whereas events within zone 3, 5 and 6 are related to the deformed belt of North Panama or the deformed belt of the southern Caribbean.

Zones 3, 5 and 6 have a small number of earthquakes and belong to the Atlantic region, and therefore they are not taken into account in this study.

Among the other three zones, zone 2 has the largest number of events, as can be observed in Fig. 4. After comparison between the AMB-AD-NOAA and the ECA tsunami catalogues over the domain resulting by the union of zones 1,2 and 4 , one can further observe that only a small portion of earthquakes was able to generate tsunamis and that the fraction of tsunamigenic earthquakes increases with the magnitude, as shown in the lower-right panel of Fig. 4.

A completeness analysis based on a method introduced by Albarello et al. (2001) was applied to the AMB-AD-NOAA earthquake catalogue in the zones 1,2 and 4. The method consists of the following steps. First, one establishes magnitude classes depending on the magnitude distribution of the historical events, and in each class counts all those events whose magnitude is within the bound limits of the class. Magnitude frequencies are given in Fig. 4.

Second, per each magnitude class one divides the time axis in intervals of 50 or 20 years, depending on the catalogue time length of each zone; and plots the number of events occurring in each time interval in complementary cumulative graphs. Finally, those time intervals that fit a trend defined by a straight line going to zero at the present time are considered as complete. The completeness periods for each zone are shown in Figs. 5, 6 and 7 for some of the magnitude classes. These can be interpreted as the time intervals over which the data contained in the catalogue can be assumed to be a reliable representation of the actual seismicity.

Having performed the completeness analysis, the GR coefficients were computed for each zone. The traditional cumulative GR magnitude-frequency relation has the following expression:

$\log N=a-b M$

where $N$ is the expected number of events with magnitude larger than $M$, and $a$ and $b$ are coefficients that are constant for a seismic homogeneous zone. The parameter $a$ is associated with the seismic activity of a particular region, whereas $b$ is the power-law exponent of scaling.

The above GR equation has been modified in order to account for the maximum possible magnitude that may occur within each zone and that is assumed to be larger than the maximum observed magnitude. The modified or truncated 

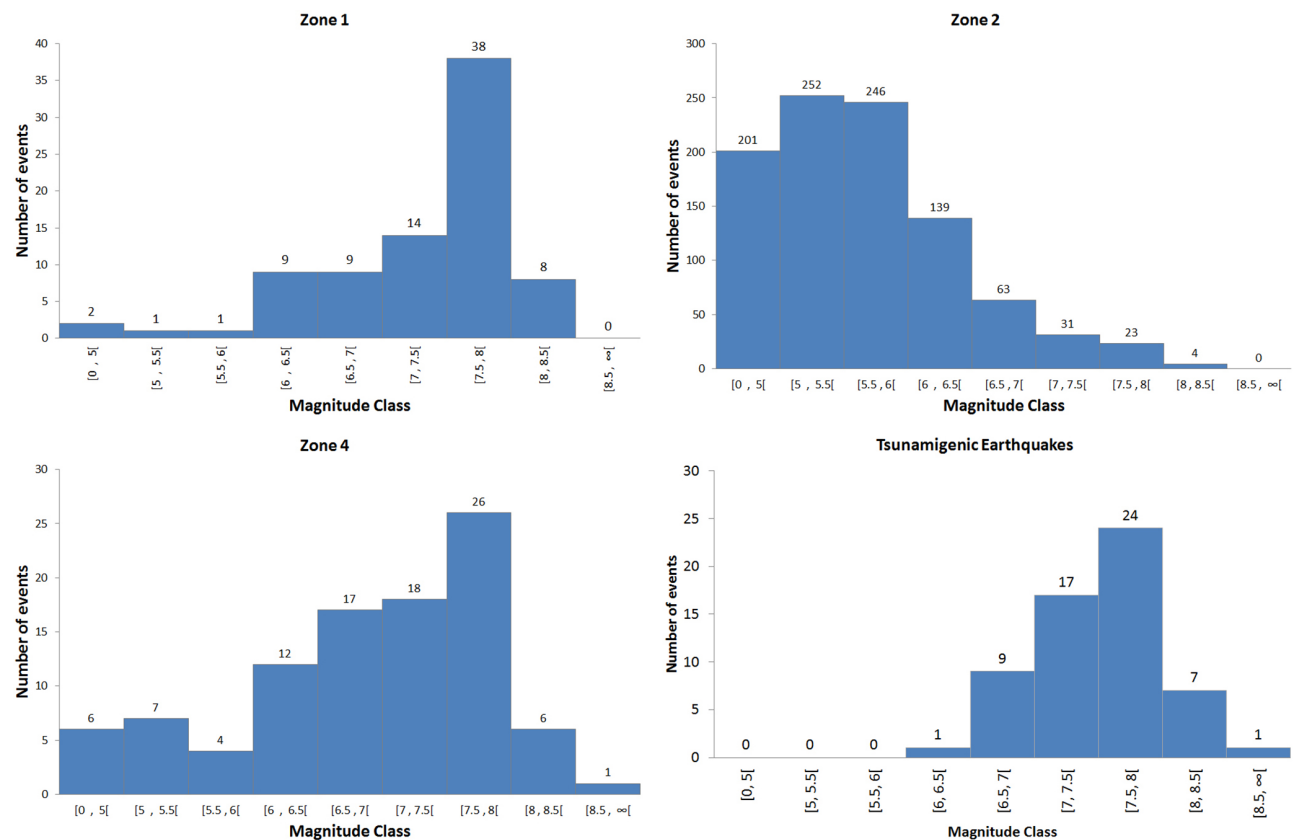

Figure 4. Magnitude frequencies in zones 1, 2 and 4. The lower-right panel shows the frequencies of tsunamigenic earthquakes in the three zones considered together.
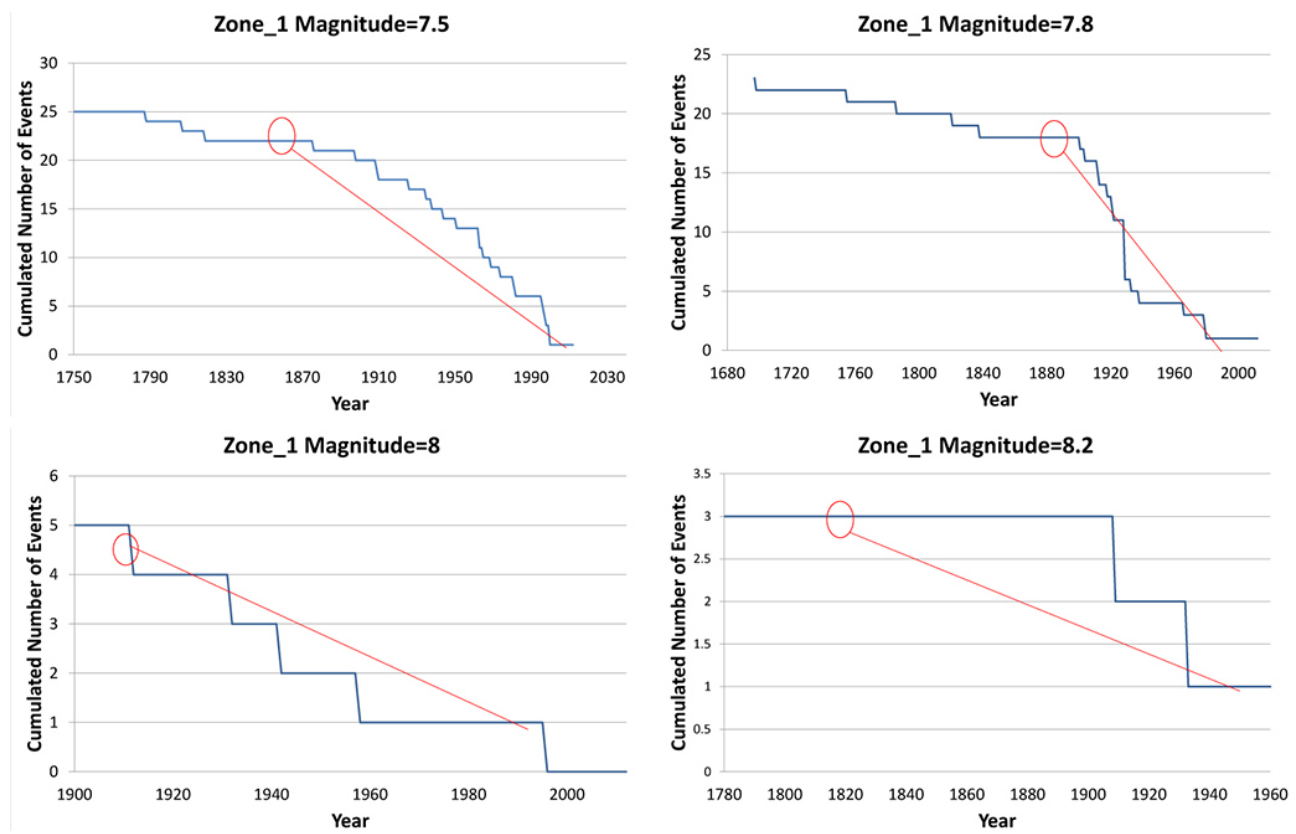

Figure 5. Completeness analysis, zone 1.

cumulative GR equation has the expression

$\log N=a+\log ?\left(\frac{e^{-\beta M}-e^{-\beta M_{\max }}}{e^{-\beta M_{\min }}-e^{-\beta M_{\max }}}\right)$

with $\beta=\left(\frac{b}{\log (e)}\right)$.

Here $M_{\min }$ is the lower bound of the magnitude interval where the GR coefficients are estimated and $M_{\max }$ is the maximum magnitude value expected for the zone studied. Incidentally, we observe that Eq. (2) exhibits the exponentially tapered functional form recommended by Kagan (2002) (see also the discussion in Geist et al., 2009). 
Table 2. GR Coefficients and magnitude boundary values.

\begin{tabular}{lrrrr}
\hline & $a$ & $b$ & $M_{\min }$ & $M_{\max }$ \\
\hline Zone 1 & 0.001 & 1.914 & 7.3 & 8.5 \\
Zone 2 & 0.737 & 0.678 & 6.0 & 8.7 \\
Zone 4 & -0.543 & 1.282 & 7.4 & 8.7 \\
\hline
\end{tabular}

The values of $a$ and $b$ obtained for zones 1,2 and 4 and the magnitude range used for the estimation are shown in Table 2.

From the cumulative GR relation, one can deduce the corresponding non-cumulative law and hence compute the annual rate of occurrence of an earthquake for any given magnitude range, even below the estimation interval of the law, though extreme back extrapolation can lead to unreliable estimates. In this work we have used the cumulative distributions. The annual rate of occurrence is simply $N$, where $N$ is the number of events, resulting from the application of the cumulative GR relation, and the corresponding return period is $1 / N$.

\section{Tsunami hazard assessment}

The occurrence rate of the earthquakes in each zone established by means of the statistical analysis described in the previous section is used as input for the second part of our approach, consisting of a simplified deterministic procedure.

In general, deterministic procedures adopted in tsunami modelling foresee a sequence of steps that, in a nutshell, can be summarised as follows: first one derives the fault parameters from the magnitude of an earthquake through proper regressions (e.g. Wells and Coppersmith, 1994; Blaser et al., 2010; Leonard, 2010; Strasser et al., 2010), then the vertical sea floor displacement, then the initial condition of the generated tsunami, and then the amplification of the tsunami at the coast through hydrodynamical methods if the bathymetry is known. This sequence of actions is usually adopted when the generation and propagation of individual tsunamis are studied by means of tsunami simulation models. Indeed, given a well-defined earthquake source (fault geometry, co-seismic slip distribution, etc.) and a properly detailed bathymetry, one applies a tsunami model to compute the propagation of a tsunami, including amplification and run-up at certain coastal targets (see for example how to build and handle tsunami scenarios in Tinti et al., 2011; see also, among the others, Tinti and Armigliato, 2003; Tinti et al., 2005; Løvholt et al., 2006, 2012a, b; Lorito et al., 2008; Tonini et al., 2011; Harbitz et al., 2012). The full application of such a scheme requires a very large computational load if one likes to treat sources differing in magnitude, fault geometry, slip distribution and location, just to mention a few variables, since it implies handling a very large number of individual scenarios.
In this paper we drastically simplify the approach by considering a number of assumptions. We first discuss the main points of the approach in general terms, and then we discuss its application to the specific case. The main assumptions are (i) that all tsunamigenic earthquakes occur along the offshore trench, with strike aligned with the trench and fault mechanism compatible with the subduction occurring in the trench and, further, (ii) that the occurrence rate of such earthquakes can be inferred from the GR relationships assessed for each zone corrected by means of a reduction factor. We recall that the GR laws provide estimates of earthquake occurrence no matter if they are tsunamigenic or not, and so the reduction factor is needed to exclude all earthquakes that cannot generate tsunamis. There are basically two ways to assess this reduction factor. The first is to compare the tsunami and the earthquake catalogues. We have made this evaluation per magnitude classes. Since the number of tsunami events is limited we have assessed the magnitude class fraction over the whole region covered by the catalogue (i.e. the region of the zone $1+$ zone $2+$ zone 4 ) rather than on a zone basis. The results are displayed in the lower-right panel of Fig. 4, which clearly shows that (1) no tsunamigenic potential exists for magnitudes lower than 6 ; (2) the potential is very low for magnitudes between 6 and 7; and (3) the fraction of tsunamigenic earthquakes increases for the magnitude classes $7 \leq M<8$ and $M \geq 8$ and can be easily derived by comparing the numbers contained in the panels of Fig. 4. This first type of approach provides a sort of lower limit for the searched reduction factor. The second approach consists in mapping the epicentres of all earthquakes in the catalogue and in evaluating the tsunamigenic potential per magnitude class based on the position of the epicentres, whether offshore or inland. We carried out this exercise for the classes $7 \leq M<8$ and $M \geq 8$, finding that the expected fraction of tsunamigenic earthquakes would be very similar for the two classes and close to $2 / 3$. This is much larger than the result found through the first type of approach, and one reason can be found in the fact that not all offshore earthquakes have focal mechanisms suitable to generate tsunamis. If we put together the findings from the two approaches, we may draw as a reasonable and conservative conclusion that, since the catalogue of tsunamis is very likely complete for the $M \geq 8$ class, and since the fraction of offshore vs. inland earthquakes is similar between the two classes $7 \leq M<8$ and $M \geq 8$, then the fraction of tsunamigenic earthquakes retrieved for the $M \geq 8$ class can be extended to the lower class $7 \leq M<8$, ascribing the difference to the incompleteness of the tsunami catalogue in that magnitude range.

Knowing this reduction factor, we have estimated the activity rate of tsunamigenic earthquakes by multiplying the number of earthquakes resulting from the truncated GR relationship deduced in the previous section by this factor.

In order to consider distinct local analyses within each zone we divide the trench in a number of segments and we adapt (i.e. reduce) the zone activity rate for each segment by 

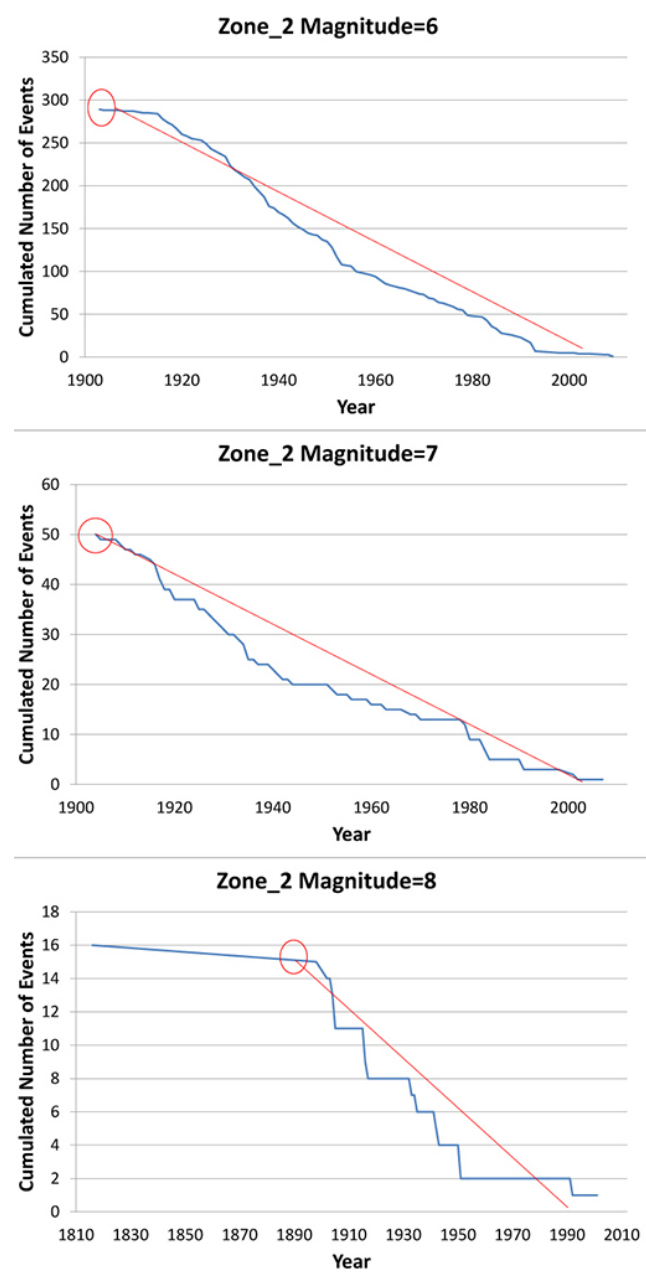

Figure 6. Completeness analysis, zone 2.

means of a proper normalisation procedure in such a way that the total number of tsunamigenic earthquakes expected in the zone is not altered. We associate each sector with a bathymetry profile or transect from the trench to the coast running in a direction preferentially normal to the trench. In this way we "maximise" the effect of the tsunami generation or, in other words, we put the emphasis on the directivity of the tsunami source. We assume that the earthquake epicentre is located offshore in the trench region and that the largest sea floor displacement induced by the earthquake occurs along the profile. Further, we assume that the vertical coseismic sea floor displacement is equal to the vertical displacement of the sea surface. Hence we are able to compute the initial sea surface wave profile along the bathymetric transect and we compute how the initial wave amplitude is amplified while approaching the coast following the bathymetric profile. In doing this we assume a 1-D tsunami propagation towards the coast, that is, however, accommodated by a 2D propagation with the application of a suitable reducing factor accounting for wave geometrical spreading. Following
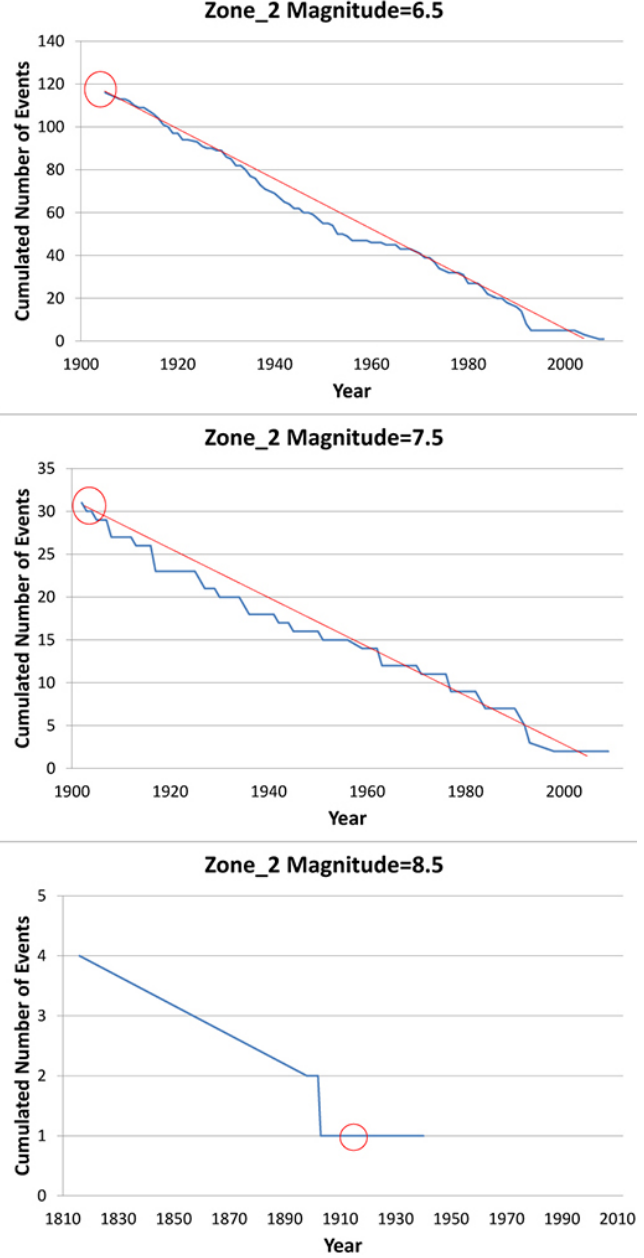

Comer (1980), such a factor can be taken to coincide with the square root of the ratio between the fault length corresponding to a given magnitude and the total profile length. As a consequence, long nearshore sources will experience minor or even no spreading, while stronger attenuation will be applied to shorter faults associated with lower magnitudes.

This strategy allows us to build a one-to-one association between each trench sector and a coastal segment, by means of the link formed by the bathymetric profile. Furthermore, we are allowed to build an association between each magnitude and the corresponding maximum wave height or a run-up height at the coast for each trench sector. Therefore, the statistics on earthquake magnitude based on the adapted GR relation can be transferred to the tsunami run-up height at the coast.

In the following we show the application of this approach and we discuss further the inherent approximations and implications.

We start with the partition of the zones in segments following the trench. We have divided the part of the CA trench 

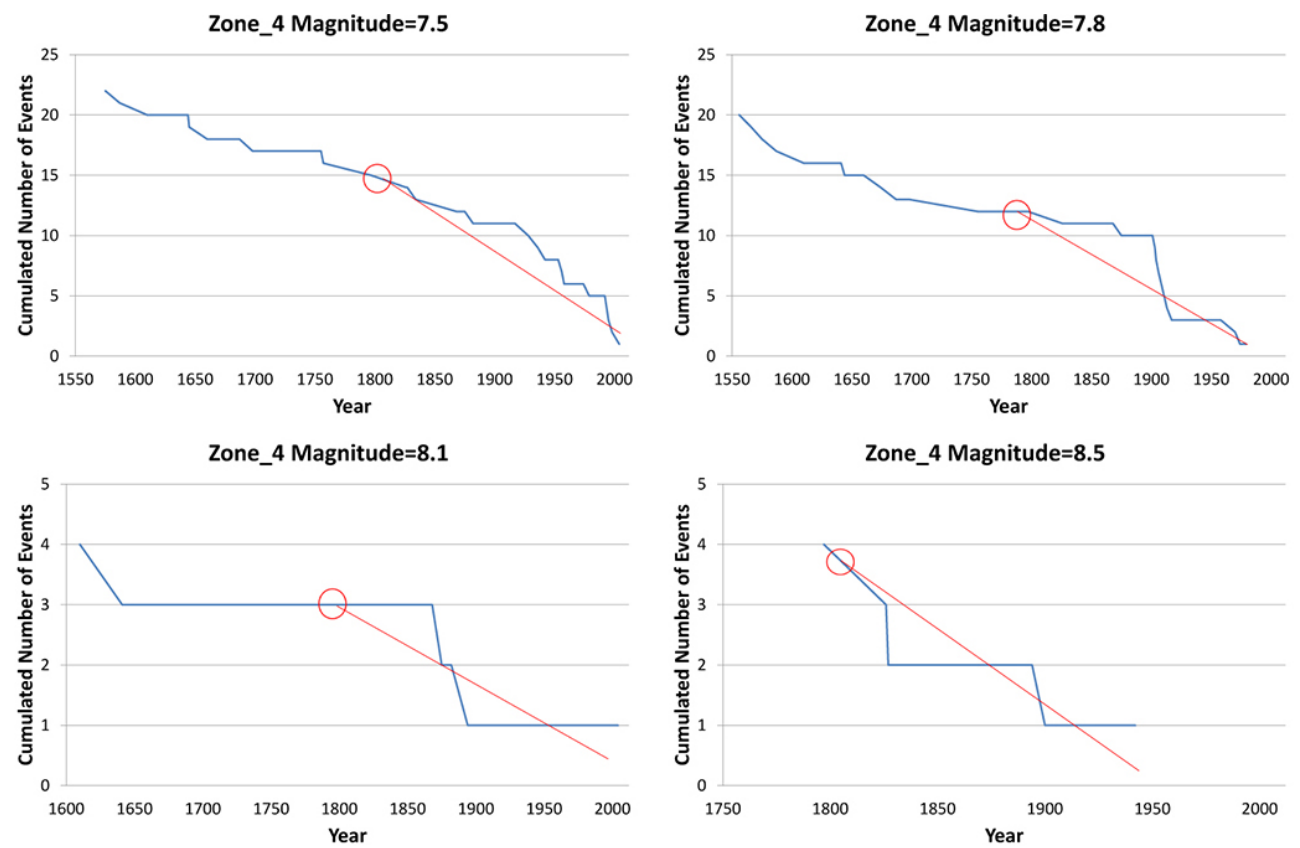

Figure 7. Completeness analysis, zone 4.

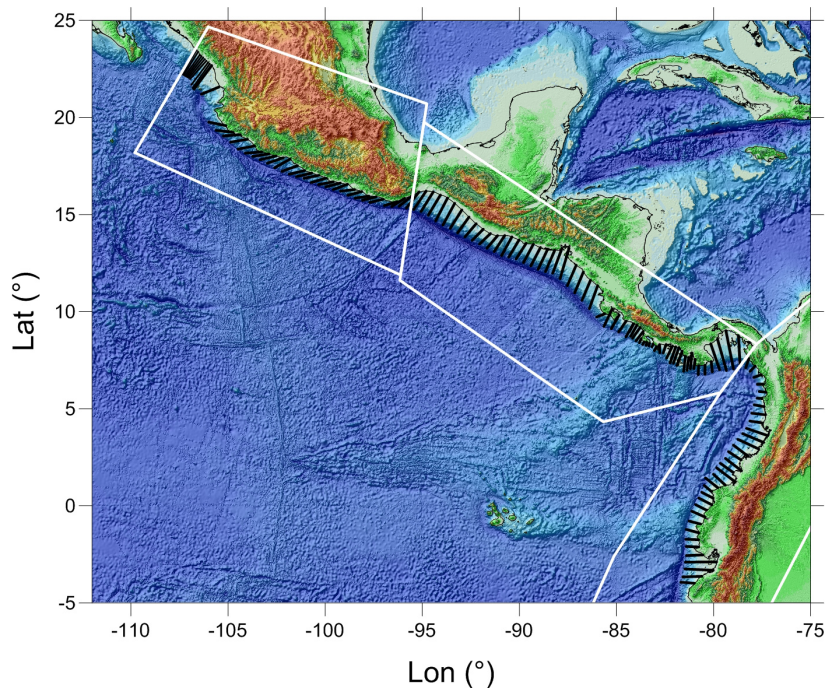

involving the two main phases of wave amplification, that is the one produced by the propagation from deep waters to the continental shelf, and from the shallower part of the continental shelf up to the coast. The main limitations related to this choice are obviously that we smooth all details of the complex subduction zone-coastal zone transition, but it can be acceptable as long as we are looking for regional-scale effects. The first starts from a depth chosen depending on the region and on the particular local bathymetry characteristics (varying between 3000 and $1000 \mathrm{~m}$ ), and ends at a depth of $20 \mathrm{~m}$. The details on the profile length and slope do not matter for this first ramp in our analysis, as will become clear later on. The second ramp starts at a depth of $20 \mathrm{~m}$ and ends at the coast. For this second ramp we are interested in computing the slope, since it will enter the amplification formula for the run-up computation. This oversimplified bathymetry will be used to compute the amplification of the tsunami approaching the coast. It is fair to comment here that the idea of using idealised piecewise bathymetric profiles along transects dates back at least to Kanoglu and Synolakis (1998) and was also recently used by Løvholt et al. (2012a, b).

A second step consists in the deterministic assessment of falling in the three zones under study in as many as 130 segments and we have correspondingly taken 130 bathymetric profiles, whose spatial distribution along the trench line is shown in Fig. 8. The transect lengths change remarkably from one region to the other, since they depend upon the variable distance of the trench from the coast.

The bathymetric profiles along the transects, though quite different from each other, can nonetheless be approximated by two ramps. In our case, the adoption of only two ramps can be considered a reasonable zeroth-order approximation 
especially on subduction zone earthquakes. Future studies may investigate on the dependence of the final results on the choice of the regressions. In addition, by inverting the Hanks and Kanamori (1979) formula

$M=\frac{2}{3} \log M_{0}-10.7$

one can derive the seismic moment $M_{0}$ (in dyne-cm) from the earthquake moment magnitude $M$, and then estimate the average slip $u$ on the fault through the relationship $M_{0}=A \mu u$, where $A$ is the fault area and $\mu$ is the rigidity (or shear modulus) of the crust, assumed in this case to be equal to $3 \times 10^{10} \mathrm{~Pa}$. It should be noted that the choice of the shear modulus value is not at all trivial: the value chosen here is mainly based on the results by Geist and Bilek (2001), who noticed that values even as small as $1-2 \times 10^{10} \mathrm{~Pa}$ are found in the literature for tsunamis generated in subduction zones (e.g. see Satake, 1995 for the 1992 Nicaragua tsunami and Tanioka and Satake, 1996, for the 1896 Sanriku tsunami). To maximise the effect of the earthquake on the vertical deformation of the sea floor, we have assumed that all earthquakes are shallow events with the upper edge of the fault placed at a depth of $20 \mathrm{~km}$ that remains fixed for every magnitude. In addition, the assumption of low-angle faults is made (dip varying between 15 and $30^{\circ}$ ) which is quite typical of many trench faults located in the shallow portion of the slab. To approximately reproduce the different geometrical characteristics of the subducting slab, we assigned dip angles of 20,16 and $29^{\circ}$ to zone 1 , zone 2 and zone 4 , respectively. Finally, through the Okada (1992) model one can compute the maximum positive vertical displacement of the sea floor $u_{z}^{\max }$. If one supposes that this is equal to the vertical displacement of the sea surface, this value can be further taken as the positive amplitude of the tsunami wave in the source region. It is worth pointing out that on making this approximation, we basically neglect the complex lithospheric structure typical of the subduction zones, where both vertical and lateral heterogeneities and irregular sea bottom topography can play a non-negligible role and can be accounted for only by means of specific models (see e.g. coseismic deformations computed through FE modelling vs. Okada model for the Tohoku 2011 earthquake in Grilli et al., 2013). In doing so, we further neglect the low-pass filtering effect of the body of water on the sea floor deformations, tending to cut short wavelengths through the reduction factor sech $(k h), h$ being the water depth and $k$ the wavenumber (see Kajiura, 1963), that is therefore more relevant for small-size sources than for large-magnitude earthquakes.

Hence, for each transect and depending on the magnitude, the initial tsunami positive amplitude is reduced by a factor equalling the square root of the ratio between the fault length corresponding to that magnitude and the total profile length. The physical basis for this reduction is to be found in the work by Comer (1980) and represents the spreading that the tsunami experiences during its propagation from the source.
We are then ready to compute the amplification experienced by the tsunami wave from the source region up to the coast. The tsunami amplitude obtained from the previous step is first amplified along the first ramp by means of the classical Green's formula:

$\frac{\eta_{2}}{\eta_{1}}=\left(\frac{H_{1}}{H_{2}}\right)^{\frac{1}{4}}$,

where $\eta_{1}$ and $\eta_{2}$ are the wave heights at depths $H_{1}$ and $H_{2}$, with $H_{1}>H_{2}$. In our case, $H_{1}$ varies between 3000 and $1000 \mathrm{~m}$, depending on the zone and specific profile, while $H_{2}$ is $20 \mathrm{~m}$. Furthermore, $\eta_{1}$ is the wave height obtained after correcting the initial tsunami positive amplitude by the spreading factor, as described above. Note that no information of the bathymetry profile between $H_{1}$ and $H_{2}$ is needed at this stage.

Finally, the run-up at the coast was estimated using a modified version of the amplification formula by Pelinovsky and Mazova (1992) (see Eq. 27 in their paper), that can be written as follows:

$\frac{\eta_{3}}{\eta_{2}}=2 \pi \sqrt{\frac{2 H_{2}}{\lambda \alpha}}$

where $\eta_{3}$ is the final amplification (or run-up), $\eta_{2}$ is the wave height computed previously at the depth $H_{2}=20 \mathrm{~m}, \lambda$ is the wavelength and $\alpha$ is the (average) slope of the second ramp.

\section{Results and discussion}

At the end of the analysis, by combining the results obtained for the rate of tsunamigenic earthquakes on a trench segment and the generation and amplification of the tsunami along the corresponding profile to the coast, we can calculate the occurrence probability of run-up exceeding a given value for the corresponding coastal segment as well as other related quantities, including the run-up distribution along the coast corresponding to a given return period, which is very important for engineering and civil protection reasons. This is plotted in Figs. 9 and 10. The first provides a comparative view of the lowest value for the maximum expected run-up for different recurrence times in a geographical perspective, while Fig. 10 shows a simplified 2-D representation of the expected run-up height distribution along the coast of the ECA from central Mexico to northern Peru, embracing the entire Pacific coast of Central America.

There are a number of considerations that can be made regarding these graphs.

First, it seems clear that the expected run-up heights along the coast are quite unequally distributed and that in some segments the values are much larger than in others. Though there is a local variability (run-up may change from one segment to the next) that is probably linked to the method of analysis and should be investigated deeper, nonetheless one can 

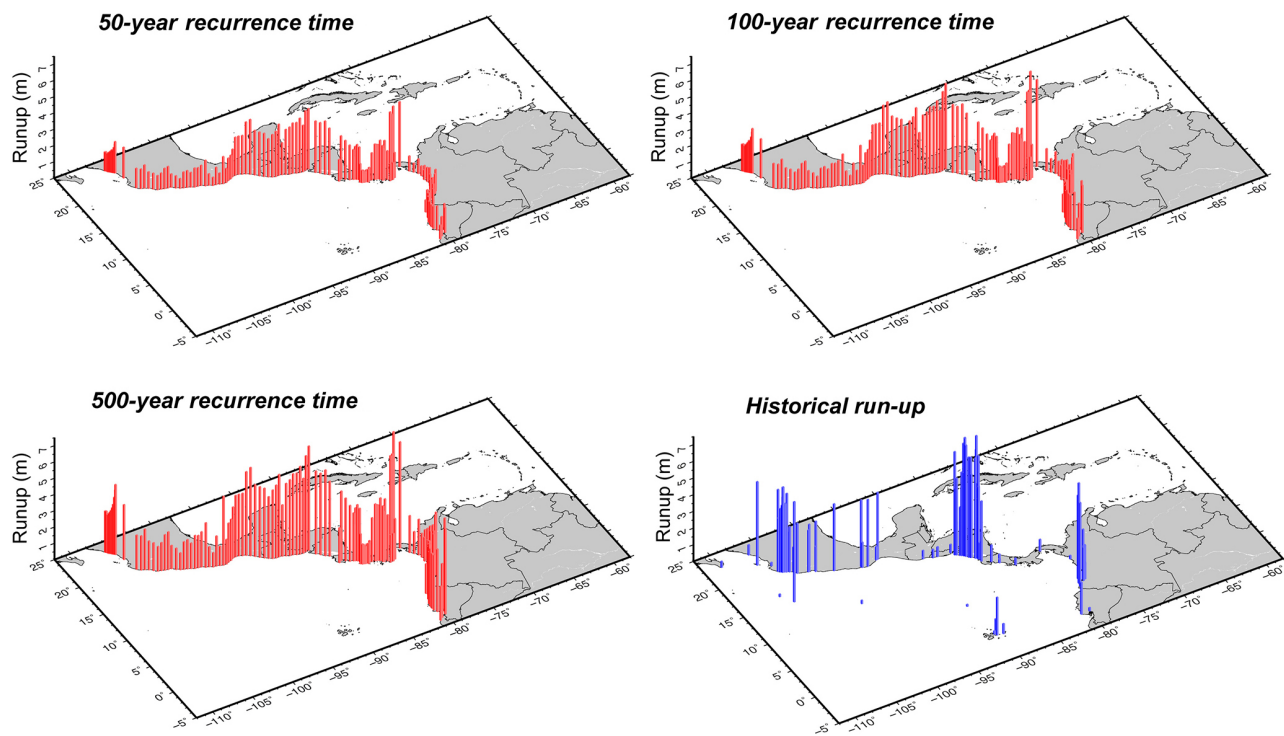

Figure 9. Maximum expected run-up height distribution for different return periods and observed historical run-up heights.

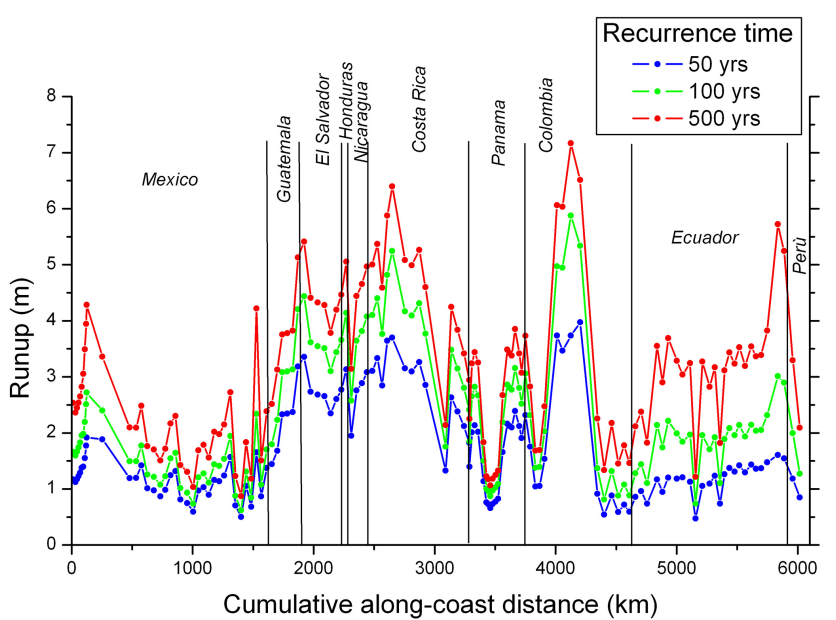

Figure 10. Maximum expected run-up distribution vs. distance along the coast.

identify some trends and behaviour over larger scales (that is involving several adjacent coastal segments).

Second, the computed values of run-up are not extremely large. The largest run-up does not exceed $10-11 \mathrm{~m}$ in 500 years, and is lower than $2 \mathrm{~m}$ in 50 years everywhere else (see Fig. 10), which are values significantly smaller than the ones observed worldwide. For example, the tsunami run-up database managed by NOAA, (http://www.ngdc.noaa.gov/ nndc/struts/form?t=101650\&s $=167 \& d=166)$ counts as many as 68 tsunami events since 1900 that were able to produce run-up higher than $10 \mathrm{~m}$ in the coasts of the world oceans, and as many as 11 events that took place since 2000 . Therefore, it seems that run-up values higher than $10 \mathrm{~m}$ are more frequent elsewhere than in the coasts of the region under analysis in this paper.

Third, the countries where run-ups are expected to be higher are southern Guatemala, El Salvador, Honduras, Nicaragua and Costa Rica in central America, and also in the central Pacific Colombia, while they are assessed to be modest (usually less than $3 \mathrm{~m}$ in 500 years) in the central portion of Mexico and Panama and in southern Colombia.

Fourth, the expected run-up heights are an increasing function of the return time, which is a trivial observation. It is worth observing, however, that the difference between the 50-year run-up and the 100-year run-up is, in a very few places, larger than the difference between the 500-year runup and the 100-year run-up, which is due essentially to the fact that those run-ups are caused by earthquakes with a magnitude close to the upper limit of the truncated frequencymagnitude GR law. Practically, a magnitude saturation implies a saturation of the tsunami height offshore and a saturation of the run-up at the coast.

Last, but probably the most important point, Fig. 9 provides a way to estimate, at least qualitatively, the performance of our approach. The lower-right panel of Fig. 9 contains the historically observed maximum run-ups as reported in the NOAA/NGDC tsunami run-up database. When comparing the simulated and the historical results, we must keep in mind that the three recurrence time plots contain the lowest value for the maximum expected run-up. The order of magnitude of the largest run-ups is well reproduced in the 500-year recurrence time plot, although it must be pointed out that there are discrepancies in the geographic distribution of the maxima. The most critical regions are Panama, northern Colombia and Ecuador, where we have very little historical information and low maximum observed run-ups, while 
our computations indicate, especially for Panama, large runups over a 500-year period. In all the other regions, historical and computed results are generally compatible. It must be stressed, however, that the geographic distribution of the historical run-ups suggests a large level of incompleteness of the tsunami catalogue for several coastal regions in the ECA domain. Other sources of possible discrepancies are discussed in the following points.

The analysis we performed and present here accounts only for run-ups associated with local tsunamigenic earthquakes that occur in front of the coast under study. Inundations caused by remote sources, located for example far away on the other side of the Pacific, or by sources that are found in the trench but remarkably shifted to the north or to the south, are not considered here. And equally not considered are sources different from earthquakes. In principle this may appear a severe limitation, and indeed it has to be removed in more accurate future studies, but for a preliminary assessment, though crude, it can be accepted since historical records have shown that all the largest recorded runups in the coasts of the countries studied here are due to local earthquakes, with sources less than $150 \mathrm{~km}$ away from the affected coast. Gonzalez et al. (2009) found that in the case of the Cascadia subduction zone, local sources dominate the 500-year return period maximum amplitudes, while far-field sources appear to be relevant for the 100-year return period. This is not always true, however. If we consider for instance central and southern Peru (a country just to the south of the region analysed here), we can find run-up values larger than $5 \mathrm{~m}$ caused by Chilean earthquakes, that is earthquakes with sources that are more than $1000 \mathrm{~km}$ away (http://www.ngdc.noaa.gov/hazard/tsu.shtml).

A further limitation of the present analysis is that it does not take into account the occurrence of the tsunami earthquakes, that is of those earthquakes that are able to cause tsunamis much larger than expected solely on the basis of their magnitude. They were first identified by Kanamori (1972) and studied later by several researchers (see Okal and Newman, 2001 for a review) and pose a serious puzzle both for tsunami hazard assessment and tsunami early warning systems. Though the cause of tsunami earthquakes is not certain yet, it seems that they are characterised by slow rupture processes that can be revealed among other means by a deficiency in generation of $\mathrm{T}$ waves compared to reference earthquakes of the same moment magnitude (see Okal et al., 2003).

These earthquakes are quite rare and very few so far have been recognised as belonging to this category. It is worth stressing that two of them have occurred in our region, i.e. the 1932 Manzanillo, Mexico tsunami and the 1992 Nicaragua tsunami. The first of the two that was described as a tsunami earthquake was the 1992 tsunami that occurred on 2 September in Nicaragua following a $M=7.7$ earthquake, causing average run-ups between 3 and $7 \mathrm{~m}$, but with extremes exceeding $10 \mathrm{~m}$ (Satake, 1995; Piatanesi et al., 1996; NOAA run-up database). The second was interpreted as a tsunami earthquake only recently and can be seen as one of the latest additions to the category (Okal and Borrero, 2011). The 22 June 1932 earthquake was a $M=7.0$ aftershock of the big Jalisco $M=8.2,3$ June earthquake that caused more than 400 fatalities in Mexico close to the border with Guatemala. In spite of the relatively moderate magnitude, the aftershock triggered a tsunami larger than the main shock. The 3 June tsunami hit Bahia San Pedrito in Manzanillo, with reported run-ups at most about $3 \mathrm{~m}$, while the 22 June tsunami hit and destroyed the little coastal city of Cuyutlán, killing more than 100 people with waves reported to be about $10 \mathrm{~m}$ high (Farreras and Sanchez, 1991).

Another remark is that our analysis cannot take into account very local amplification effects of tsunami waves. In this paper a coastal zone as long as $6000 \mathrm{~km}$ has been divided into 130 coastal segments that are separated by $45 \mathrm{~km}$ on average, and the resulting resolution is not enough to capture the high variability of the coastal topo-bathymetric and geomorphological features that, as is well known, influence the tsunami flooding and run-up. The comparison of the results presented here, with much more detailed and refined numerical simulation outputs, is left to a possible future study.

\section{Conclusions}

In this paper we have applied a hybrid method to assess the tsunami hazard on the coast of a long zone of Pacific America running from Central Mexico to northern Peru that we call Extended Central America. The "hybrid" denotation refers to the fact that we have used probabilistic methods to assess the rate of occurrence of earthquakes, whereas we have made use of deterministic simple formulas to evaluate the tsunami amplification at the coast, given that an earthquake of a given magnitude has occurred in a given place, following an idea introduced by Tinti (1991a) for tsunami hazard computations in Italy.

Our analysis has to be considered preliminary or "expedite", since computations could be simple and quick by exploiting a number of assumptions, regarding the frequency magnitude law (a truncated GR was assumed), the empirical regression law connecting the fault parameters and the magnitude, the 1-D propagation of tsunami along transects or profiles, made less stringent by the application of a spreading factor, the oversimplification of the bathymetry along the profiles.

From a physical point of view, the most relevant limitation is that we restrict the analysis only to local earthquake sources, occurring along the trench, and also discard tsunami earthquake mechanisms, though there are at least two examples of such earthquakes in the seismic history of the region. Regarding the first point, we cited the findings by Gonzalez et al. (2009) in the previous section, i.e. local sources dominating the 500-year return period maximum amplitudes. It 
will be interesting to go deeper into this in a future study to understand whether this behaviour is zone-dependent or instead if it represents a global trend.

Our analysis allows us to compute the probability distribution of the run-up along the coast and therefore to answer questions such as what the return time of a given run-up value is, or what the maximum run-up expected in a given return period is. In this paper we provide an example of the second type of computations in Figs. 9 and 10.

The results of our analysis is that the region we have studied is affected by moderate tsunami hazards compared to other regions in the Pacific and the Indian Ocean, where much higher run-ups are expected on the basis of historical reports, and that Central America from El Salvador to Nicaragua, as well as the central zone of Pacific Colombia, are the ones with the highest expected run-ups. The comparison with available historical data shows a general satisfactory performance of our approach, although discrepancies exist that can be ascribed partly to the several simplifications involved in our model and partly to the very likely large level of incompleteness of the historical tsunami catalogue for the ECA, especially in some regions.

The run-ups obtained with our method are to be considered average or reference values in the coastal segment for which they are computed, since they were derived by taking into account general simplified bathymetric trends offshore. Higher values could be expected in correspondence with special local features, such as at the end of narrow bays, pocket beaches, on the lee side of small islands, etc.

A complementary approach to study tsunami hazards is based on worst-case scenarios, where the largest possible "credible" tsunamis that may affect the target area are studied through numerical simulations and, when available, historical data (see e.g. Tinti and Armigliato, 2003; Tonini et al., 2011 for application in the Mediterranean Sea). The authors believe that this approach could be useful to overcome some of the limitations of the method used in this work, since it could allow for an extension of the analysis to nonearthquake sources and to account for a finer resolution on the coast. This will be the next step of the research.

Acknowledgements. This research was performed during the $\mathrm{PhD}$ program of one of the authors, namely Beatriz Brizuela, followed at the University of Bologna under the supervision of Stefano Tinti. The authors wish to thank two anonymous referees for constructive and helpful comments.

Edited by: M. Gonzalez Rodríguez

Reviewed by: two anonymous referees

\section{References}

Abe, K., Abe, K., Tsuji, Y., Imamura, F., Katao, H., Iio, Y., Satake, K., Bourgeois, J., Noguera, E., and Estrada, F.: Field survey of the Nicaragua Earthquake and tsunami of September 2, 1992, Bull. Earthq. Res. Inst., Univ. of Tokyo, 68, 23-70, 1993 (in Japanese).

Albarello, D., Camassi, R., and Rebez A.: Detection of space and time heterogeneity in the completeness of a seismic catalogue by a statistical approach: an application to the Italian area, Bull Seismol. Soc. Am., 91, 1694-1703, 2001.

Álvarez Gómez, J. A.: Tectónica Activa y Geodinámica en el Norte de Centroamérica, Ph.D. thesis, Universidad Complutense de Madrid, 2009.

Álvarez-Gómez, J. A., Gutierrez-Gutierrez, O. Q., Aniel-Quiroga, I., and Gonzalez, M.: Tsunamigenic potential of outer-rise normal faults at the Middle America trench in Central America, Tectonophysics, 574-575, 133-143, 2012.

Álvarez-Gómez, J. A., Aniel-Quiroga, Í., Gutiérrez-Gutiérrez, O. Q., Larreynaga, J., González, M., Castro, M., Gavidia, F., Aguirre-Ayerbe, I., González-Riancho, P., and Carreño, E.: Tsunami hazard assessment in El Salvador, Central America, from seismic sources through flooding numerical models., Nat. Hazards Earth Syst. Sci., 13, 2927-2939, doi:10.5194/nhess-132927-2013, 2013.

Ambraseys, N. N. and Adams, R.: The seismicity of Central America, Imperial College Press, 2000.

Baptista, A. M., Priest, G. R., and Murty, T. S.: Field survey of the 1992 Nicaragua tsunami, Mar. Geodesy, 16, 169-203, 1993.

Blaser, L., Krüger, F., Ohrnberger, M., and Scherbaum, F.: Scaling relations of earthquake source parameter estimates with special focus on subduction environment, Bull. Seismol. Soc. Am., 100, 2914-2926, doi:10.1785/0120100111, 2010.

Bommer, J. J. and Rodriguez, C. E.: Earthquake-induced landslides in Central America, Eng. Geol., 63, 189-220, 2002.

CERESIS (Centro Regional de Sismología para América del Sur): available at: http://www.ceresis.org/portal/catal_hipo.php, last access: April, 2014

Comer, R. P.: Tsunami height and earthquake magnitude: theoretical basis of an empirical relation, Geophys. Res. Lett., 7, 445448,1980

Dewey, J. W., White, R., and Hernández, D.A.: Seismicity and Tectonics of El Salvador, Natural Hazards in El Salvador: Geological Society of America Special Paper 375, 363-378, 2004.

El Alami, S. O. and Tinti, S.: A preliminary evaluation of the tsunami hazards in the Moroccan coasts, Sci. Tsunami Hazards, 9, 31-38, 1991.

Espinoza, J.: Terremotos Tsunamigenicos en el Ecuador, Acta Oceanografica del Pacifico, INOCAR, Ecuador 7, 1992.

Farreras, S. F. and Sanchez, A.J.: The Tsunami Threat on the Mexican West Coast: A Historical Analysis and Recommendations for Hazard Mitigation, Nat. Hazards, 4, 301-316, 1991.

Fernández, M., Molina, E., Havskov, J., and Atakan K.: Tsunamis and Tsunami Hazards in El Salvador, Nat. Hazards, 22, 91-116, 2000.

Fernández, M., Ortiz-Figueroa, M., and Mora, R.: Tsunami Hazards in El Salvador, Natural Hazards in El Salvador, Geol. Soc. Am Special Paper, 375, 435-444, 2004.

GEBCO website: The GEBCO_08 Grid, version 20091120, available at: http://www.gebco.net, last access: April, 2014. 
Geist, E. L. and Bilek, S. L.: Effect of depth-dependent shear modulus on tsunami generation along subduction zones, Geophys. Res. Lett., 28, 1315-1318, 2001.

Geist, E. and Parsons, T.: Probabilistic analysis of tsunami hazards, Nat. Haz., 37, 277-314, 2006.

Geist, E. L., Parsons, T., ten Brink, U. S., and Lee, H. J.: Tsunami Probability, in: The Sea, edited by: Bernard, E. N. and Robinson, A. R., Vol. 15: Cambridge, Massachusetts, Harvard University Press, 93-135, 2009.

Grilli, S. T., Harris, J. C., Tajalli Bakhsh, T. S., Masterlark, T. L., Kyriakopoulos, C., Kirby, J. T., and Shi, F.: Numerical simulation of the 2011 Tohoku tsunami based on a new transient FEM coseismic source: Comparison to far- and near-field observations, Pure Appl. Geophys., 170, 1333-1359, doi:10.1007/s00024-0120528-y, 2013.

González, F. I., Geist, E. L., Jaffe, B., Kânoğlu, U., Mofjeld, H., Synolakis, C. E., Titov, V. V., Arcas, D., Bellomo, D., Carlton, D., Horning, T., Johnson, J., Newman, J., Parsons, T., Peters, R., Peterson, C., Priest, G., Venturato, A., Weber, J., Wong, F., and Yalciner, A.: Probabilistic tsunami hazard assessment at Seaside, Oregon, for near- and far-field seismic sources, J. Geophys. Res., 114, C11023, doi:10.1029/2008JC005132, 2009.

Harbitz, C. B., Glimsdal, S., Bazin, S., Zamora, N., Løvholt, F., Bungum, H., Smebye, H., Gauer, P., and Kjekstad, O.: Tsunami hazard in the Caribbean: regional exposure derived from credible worst case scenarios, Continental Shelf Res., 38, 1-23, 2012.

Hanks, T. C. and Kanamori, H.: A moment-magnitude scale, J. Geophys. Res., 84, 2348-2350, 1979.

Iida, K.: The generation of tsunamis and the focal mechanisms of earthquakes, in: Tsunamis in the Pacific Ocean, edited by: Adams, W. M., Honolulu, Hawaii, East-West Center Press, 3-18, 1970.

Iida, K., Cox, D. C., and Pararas-Carayannis G.: Preliminary catalog of tsunamis occurring in the Pacific ocean. Hawaii Institute of Geophysics, Data Report 5, 67-10, 1967.

Kagan, Y. Y.: Seismic moment distribution revisited: I. Statistical results, Geophys. J. Int., 148, 520-541, 2002.

Kajiura, K.: The Leading Wave of a Tsunami, Bull. Earthq. Res. Inst., 41, 535-571, 1963.

Kanamori, H.: Mechanism of tsunami earthquakes, Phys. Earth Planet. Int., 6, 346-359, 1972.

Kanoglu, U. and Synolakis, C. E.: Long wave runup on piecewise linear topographies, J. Fluid Mech., 374, 1-28, 1998.

Kostoglodov, V. and Pacheco J. F.: Cien años de sismicidad en Mexico, available at: http://usuarios.geofisica.unam.mx/ vladimir/sismos/100a\%F1os.html (last access: July 2014), 1999.

Leeds, J.: Catalogue of Nicaraguan Earthquakes, Bull. Seismol. Soc. Am., 64, 1135-1158, 1974.

Leonard, M.: Earthquake fault scaling: self-consistent relating of rupture length, width, average displacement, and moment release, Bull. Seismol. Soc. Am., 100, 1971-1988, doi:10.1785/0120090189, 2010.

Lorito, S., Tiberti, M. M., Basili, R., Piatanesi, A., and Valensise, G.: Earthquake-generated tsunamis in the Mediterranean Sea: scenarios of potential threats to southern Italy, J. Geophys. Res., 113, B01301, doi:10.1029/2007JB004943, 2008.
Løvholt, F., Bungum, H., Harbitz, C. B., Glimsdal, S., Lindholm, C. D., and Pedersen, G.: Earthquake related tsunami hazard along the western coast of Thailand, Nat. Hazards Earth Syst. Sci., 6, 979-997, doi:10.5194/nhess-6-979-2006, 2006.

Løvholt, F., Glimsdal, S., Harbitz, C. B., Zamora, N., Nadim, F., Peduzzi, P., Dao, H., and Smebye, H.: Tsunami hazard and exposure at the global scale, Earth Sci. Rev., 110, 58-73, 2012a.

Løvholt, F., Kühn, D., Bungum, H., Harbitz, C. B., and Glimsdal, S.: Historical tsunamis and present tsunami hazard in eastern Indonesia and the southern Philippines, J. Geophys. Res., 117, B08310, doi:10.1029/2012JB009425, 2012b.

Molina, E.: Tsunami Catalogue for Central America 1539-1996, Reduction of Natural Disasters in Central America, Technical Report, No. II 1-04, Institute of Solid Earth Physics, University of Bergen, 1997.

NOAA: National Oceanographic and Atmosferic Data, available at: www.ngdc.noaa.gov/seg/hazard/tsuintro.shtml, last access: April, 2014.

NOAA-NGDC: National Oceanic and Atmospheric Administration- National Geophysical Data Center Tsunami Event and Runup Database, available at: http://www.ngdc.noaa.gov/nndc/ (last access: June 2013), 2013.

NOAA/WDC: Tsunami Event Database, available at: http://www. ngdc.noaa.gov/nndc/struts/form?t=101650\\&s=70\\&d=7, last access: January, 2014.

NOAA/WDC: Tsunami Run-up, available at: http://www.ngdc. noaa.gov/nndc/struts/form?t=101650\\&s=167\\&d=166, last access: January, 2014.

Okada, Y.: Internal deformation due to shear and tensile faults in a half-space, Bull. Seismol. Soc. Am., 82, 1018-1040, 1992.

Okal, E. A. and Borrero, J. C.: The 'tsunami earthquake' of 1932 June 22 in Manzanillo, Mexico: seismological study and tsunami simulations, Geophys. J. Int., 187, 1443-1459, 2011.

Okal, E. A. and Newman, A. V.: Tsunami earthquakes: The quest for a regional signal, Phys. Earth. Planet. Int., 124, 45-70, 2001.

Okal, E. A., Alasset, P. J., Hyvernaud, O., and Schindelé, F.: The deficient $\mathrm{T}$ waves of tsunami earthquakes, Geophys. J. Int., 152, 416-432, 2003.

Pelinovsky, E. N. and Mazova, R. KH.: Exact analytical solutions of nonlinear problems of tsunami wave run-up on slopes with different profiles, Nat. Haz., 6, 227-249, 1992.

Peraldo, G. and Montero, W.: Sismología histórica de América Central, Insituto Panamericano de Geografía e Historia, (IPGH), México, Publ. No. 513, 342 pp., 1999.

Phipps Morgan, J., Ranero, C. R., and Vannucchi, P.: Intra-arc extension in Central America: Links between plate motions, tectonics, volcanism, and geochemistry, Earth Planet. Sci. Lett., 272, 365-371, 2008.

Piatanesi, A., Tinti, S., and Gavagni, I.: The slip distribution of the 1992 Nicaragua earthquake from tsunami data, Geophys. Res. Lett., 23, 37-40, 1996.

Power, W., Downes, G., and Stirling, M.: Estimation of tsunami hazard in New Zealand due to South American Earthquakes, Pure Appl. Geophys., 164, 547-564, 2007. 
Ranero, C. R., Weinrebe, W., Grevemeyer, I., Morgan, J. P., Vannucchi, P., and Von Huene, R.: Tectonic Structure of the Middle America Pacific Margin and Incoming Cocos Plate from Costa Rica to Guatemala, Geophys. Res. Abstracts, 6, 05185, European Geosciences Union, 2004.

Restrepo, J. C. and Otero, L. J.: Modelacion Numerica de Eventos Tsunamigenicos en la Cuenca Pacifica Colombiana- Bahia de Buenaventura, Rev. Acad. Colomb. Cienc.: XXXI, Num. 120Sept, 363-377, 2007.

Rojas, W.: Catálogo de sismicidad histórica y reciente en América Central, desarrollo y análisis, Tesis de Licenciatura en Geología (Universidad de Costa Rica, San José), 91 pp., 1993.

Satake, K.: Mechanism of the 1992 Nicaragua tsunami earthquake, Geophys. Res. Lett., 21 2519-2522, 1994.

Satake, K.: Linear and nonlinear computations of the 1992 Nicaragua earthquake tsunami, Pure Appl. Geophys., 20, 863866, 1995.

Satake, K., Bourgeois, J., Abe, K., Abe, K., Tsuji, Y., Imamura, F., Iio, Y., Katao, H., Noguera, E., and Estrada, F.: Tsunami field survey of the 1992 Nicaragua earthquake, Eos Transactions, Am. Geophys. Union, 74-13, 145-160, 1993.

Singh, S. K., Rodriguez, M., and Espindola, J. M.: A Catalog of Shallow Earthquakes of Mexico from 1900 to 1981, Bull. Seismol. Soc. Am., 74, 267-279, 1984.

Singh, S. K., Pérez-Campos, X., Iglesias, A., and Pacheco, J. F.: An exploratory study for rapid estimation of critical source parameters of great subduction-zone earthquakes in Mexico, Geofís. Intl., 47, 355-369, 2008.

SSN: Servicio Sismologico Nacional, available at: http://www.ssn. unam.mx/ (last access: May 2013), 2013.
Strasser, F. O., Arango, M. C., and Bommer, J. J.: Scaling of the source dimensions of interface and intraslab subduction-zone earthquakes with moment magnitude, Seismol. Res. Lett., 81, 941-950, doi:10.1785/gssrl.81.6.941, 2010.

Suárez, G. and Albini, P.: Evidence for Great Tsunamigenic Earthquakes (M 8.6) along the Mexican Subduction Zone, Bull. Seismol. Soc. Am., 99, 892-896, doi:10.1785/0120080201, 2009.

Tanioka, Y. and Satake. K.: Fault parameters of the 1896 Sanriku tsunami earthquake estimated from tsunami numerical modeling, Geophys. Res. Lett., 23, 1549-1552, 1996.

Tinti, S.: Assessment of tsunami hazard in the Italian Seas, Nat. Hazards, 4, 267-283, 1991a.

Tinti, S.: Tsunami potential in Southern Italy, Sci. Tsunami Hazards, 9, 5-14, 1991b.

Tinti, S. and Armigliato, A.: The use of scenarios to evaluate tsunami impact in South Italy, Mar. Geol., 199, 221-243, 2003.

Tinti, S., Armigliato, A., Pagnoni, G., and Zaniboni, F.: Scenarios of giant tsunamis of tectonic origin in the Mediterranean, ISET J. Earthquake Technol., 42, 171-188, 2005.

Tinti, S., Tonini, R., Bressan, L., Armigliato, A., Gardi, A., Guillande, R., Valencia, N., and Scheer, S.: Handbook of tsunami hazard and damage scenarios, JRC Scientific and Technical Reports, 1-41, doi:10.2788/21259, 2011.

Tonini, R., Armigliato, A., Pagnoni, G., Zaniboni, F., and Tinti, S.: Tsunami hazard for the city of Catania, eastern Sicily, Italy, assessed by means of Worst-case Credible Tsunami Scenario Analysis (WCTSA), Nat. Hazards Earth Syst. Sci., 11, 1217-1232, doi:10.5194/nhess-11-1217-2011, 2011.

Wells, D. L. and Coppersmith, K. J.: New empirical relationships among magnitude, rupture length, rupture width, rupture area, and surface displacement, Bull. Seismol. Soc. Am., 84, 974 1002, 1994. 